ARQGA / 942

\title{
HEPATITE CRÔNICA POR VÍRUS C Parte 1. Considerações gerais
}

\author{
Vinício Paride CONTE*
}

RESUMO - O virus da hepatite C foi identificado em 1989 como sendo o principal agente causador das hepatites não-A não$B$ e o seu reconhecimento como agente de alta prevalência nas infecções pós-tranfusionais elou uso de derivados do sangue ou em associação com o abuso de drogas endovenosas. A descoberta e a maior disponibilidade de novas técnicas para a seleção adequada de doadores de sangue, reduziu sensivelmente a incidencia das hepatites pós-transfusionais. Cerca de 95\% dos individuos infectados pelo vírus da hepatite C podem ser identificados pelos testes anti-vírus da hepatite C de terceira geração. Os estudos retrospectivos de infecções pelo vírus da hepatite C iatrogênicas, são as principais fontes de reconhecimento da história natural da doença. A distribuição dos diferentes genótipos do vírus da hepatite C varia de acordo com as regiões geográficas. Na América do Sul, Europa, Estados Unidos e Japão 1, 2, e 3 representam a maioria das infecções, sendo o subtipo 1-b o mais prevalente. Os parâmetros epidemiológicos (idade, fatores de risco e duração da infecção) podem estar associados com os genótipos do vírus da hepatite C, sendo os tipos 1-a e 3-a mais freqüentes nos drogaditos endovenosos e o 1-b nas hepatites pós-transfusionais. O subtipo 1-b ocasiona lesões hepáticas mais graves e prolongadas, com alterações ultraestruturais mitocondriais freqüentes e grande comprometimento dos processos de fosforilização oxidativa. A produção aumentada de radicais livres pode influenciar negativamente a evolução da doença hepática pelo reforço da ação citopática do vírus da hepatite C que provoca. O significado clínico dos níveis de vírus $C$ no interior do figado, nesses pacientes, não é determinado pelos fatores hospedeiro (idade, tipo e duração da infecção) ou pelos fatores virais (genótipos) e os repetidamente vírus da hepatite C RNA RT-PCR negativos no soro, não indicam necessariamente ausência de vírus da hepatite C no figado. A associação de autoimunidade à hepatite Cé questionável. Os marcadores imunes são freqüentemente detectados em baixos níveis. A modulação da resposta imune ao envelope protéico E2, após injeção de plasmídios DNA, tem sido usada para induzir respostas imunes específicas ao vírus da hepatite C. $O$ espectro de tais respostas poderia ser ampliada mediante combinação de plasmídios, vias de administração e outras formas de imunógenos codificados (vacinas a base de peptidios). Tais estratégias podem vir a ser importantes, em breve, no combate aos altamente mutantes vírus da hepatite C. O papel patogênico dos novos vírus G e TT das hepatites está em estudos, porém é de consenso que suas associações com doença hepática ativa é fortuita.

DESCRITORES - Hepatite C.

$\mathrm{O}$ vírus da hepatite $\mathrm{C}$ (VHC) foi identificado e isolado a partir de um clone derivado de um genoma NANBH, semelhante aos togaviridae ou flaviviridae, por $\mathrm{CHOO}$ et al. ${ }^{(8)}$, em 1989 e visualizado à imunoeletromicroscopia ${ }^{(14)}$, como partí- cula de 55 a $65 \mathrm{~nm}$ de diâmetro, com projeções espiculares e de morfologia muito semelhante aos flaviviridae. Além disso, estas partículas reagiram especificamente com anticorpos mono e policlonais do conteúdo protéico do envelope do VHC.

Professor Associado do Departamento de Gastroenterologia da Faculdade de Medicina da Universidade de São Paulo, São Paulo, SP.

Endereço para correspondência: Dr. Vinício Paride Conte - Av. Brigadeiro Faria Lima, 1993 - Cj. 21 - 01451-001 - São Paulo, SP. 
Antes da seleção rigorosa dos doadores de sangue, em 1991, o VHC era a maior causa de hepatite pós-transfusional. Atualmente permanece como tal em casos esporádicos.

A prevalência da infecção nos doadores de sangue sadios varia de 0,01\%-0,02\% no Reino Unido e no norte da Europa, $1 \%-1,5 \%$ no sul da Europa, 6,5\% na África equatorial e de até 20\% no Egito ${ }^{(9,10,21,25)}$. E o que é mais importante, na experiência de MUTIMER et al. ${ }^{(21)}$, cerca de $80 \%$ dos doadores sero-positivos, analisados exaustivamente, inclusive com biopsia de fígado, mostraram evidências de alterações histológicas e ou virológicas de infecção persistente sem, no entanto, atingir graus mais avançados de hepatopatia crônica, quase todos permanecendo na categoria moderada. Atualmente o VHC se constitui no maior problema de saúde pública mundial ${ }^{(5)}$.

ALTER et al. ${ }^{(3)}$, em $82 \%$ de seus 130 pacientes seguidos durante muitos anos, após surto agudo de hepatite não-A não-B, encontraram infecção VHC, anti-VHC ou VHC RNA positividade, sendo que $62 \%$ deles desenvolveram hepatite crônica e concluem que os pacientes que adquiriram hepatite $\mathrm{C}$ tiveram alto grau de hepatite crônica, sendo que o VHC pode ser a maior causa de doença crônica de fígado nos EUA e que na maioria dos pacientes a infecção VHC parece persistir por muitos anos, mesmo na ausência de doença hepática ativa.

ALMEIDA et al. ${ }^{(2)}$ determinaram a prevalência da infecção em doadores de sangue, assim como avaliaram o grau de comprometimento hepático nessa população, concluindo que de 37.335 doadores, durante o biênio 93-94, em Porto Alegre, RS, utilizando o teste antiVHC ELISA 2, selecionaram 60 deles para a biopsia hepática, com agulha de Menghini, encontrando prevalência de 1,74\%, sendo a hepatopatia crônica de graus variáveis observada em $80 \%$ deles, na sua grande maioria com lesões leves e mínimas. Foi observada forte associação entre elevação de alanina aminotransferase (ALT) e presença de hepatopatia crônica, embora a intensidade desta elevação não se correlacione com a gravidade da lesão histológica. Em cinco deles havia cirrose hepática.

Por ocasião da Conferência Internacional de Consenso sobre Hepatite $\mathrm{C}^{(18)}$, concluiu-se que a hepatite crônica por vírus $\mathrm{C}$ é um problema grave de saúde pública, sendo sua prevalência mundial estimada em $3 \%$ (de $0,1 \%$ a $5 \%$, segundo os vários países) portanto, havendo no mundo todo, cerca de 150 milhões de portadores crônicos do VHC: 4 milhões nos EUA e 5 milhões na Europa Ocidental. Na Europa Oriental a prevalência é maior ainda.

Nos países industrializados, a hepatite por vírus $\mathrm{C}$ é responsável por $20 \%$ dos casos de hepatite aguda, $70 \%$ dos de hepatite crônica, $40 \%$ dos de cirrose descompensada, $60 \%$ dos de carcinoma hepatocelular e $30 \%$ dos transplantes hepáticos.

Cerca de $40 \%$ do total de pacientes curam-se ou têm doença crônica de natureza benigna. Os restantes $60 \%$ cursam com atividade aumentada de aminotransferase, denotando evolução crônica da doença. Dentre estes, a maioria tem lesões necroinflamatórias discretas e fibrose mínima ou ausente. O prognóstico a longo prazo é mal conhecido, no entanto, provavelmente a maioria deles não virá a falecer da doença hepática em curso. Cerca de 20\% deles, depois de 10-20 anos de evolução, desenvolverão cirrose hepática, passível de transplante. Assim, a hepatite crônica por vírus $\mathrm{C}$ é doença que ocasiona a morte de um pequeno número de pacientes sem, no entanto, afetar a duração da vida média da maioria deles.

Após infecção aguda, somente $10 \%$ dos pacientes desenvolve doença clínica com icterícia. A infecção sub-clínica é a regra e, assim, passa despercebida. Cerca de $25 \%$ deles têm infecção crônica sintomática, com aminotransferases normais e lesões inflamatórias histológicas mínimas.

A remissão espontânea acontece em cerca de $15 \%$ dos casos. Na grande minoria dos casos, a progressão da doença aguda pode levar à insuficiência hepática aguda.

O risco de transmissão sexual do VHC é mínimo, raro. A contaminação intrafamilial não-sexual é considerável, particularmente quando um dos enfermos tem hepatopatia grave e ou carga viral elevada (risco $1: 10)$.

A prática de tatuagem fornece dados conflitantes, sabendo-se que os "líquidos" usados para "esterilizar" os instrumentos usados são ineficazes.

KARMOCHKINE et al. ${ }^{(16)}$ observaram que $60 \%$ a $80 \%$ dos pacientes contraem o vírus através da toxicomania intravenosa ou transfusões de sangue ou de derivados. Os restantes meios de transmissão e de contágio são a hemodiálise, os transplantes de órgãos, picadas acidentais profissionais e transmissão vertical mãe-criança. Em 20\% a $40 \%$ dos casos não se consegue determinar o modo de contaminação.

Como a transmissão da hepatite crônica por vírus $\mathrm{C}$ poderia ser prevenida?

As duas fontes de contaminação são a toxicomania endovenosa e a administração de produtos de origem sangüínea. Esta última praticamente eliminada, desde 1991, com a introdução dos testes ELISA 2, na seleção aprimorada de doadores de sangue.

A transmissão sexual é rara. Nos indivíduos com parceiros múltiplos, o uso de preservativos está indicado.

A gravidez não está contra-indicada nas mulheres infectadas pelo VHC.

A transmissão vertical mãe-criança é rara (menor de 6\%). O tipo de parto (natural ou cesárea) não tem influência. O aleitamento é permitido.

A transmissão nosocomial é prevenida eficazmente, de modo convencional.

Observações feitas por autores irlandeses ${ }^{(17)}$, comprovam a natureza e a evolução clínica da afecção em causa. Os autores acompanharam durante 17 anos, 376 mulheres que receberam injeções de imunoglobulinas anti-D, contaminadas com VHC, provenientes de doador 
único num programa de isoimunização Rh. Destas, $81 \%$ apresentaram sintomatologia, mais freqüentemente fadiga (66\%), ALT ligeiramente elevada (de 40 a $99 \mathrm{U} / \mathrm{L}$ ) em $47 \%$ e igual ou maior de $100 \mathrm{U} / \mathrm{L}$ em $8 \%$. A biopsia hepática mostrou inflamação em $98 \%$ delas, na maioria das vezes, leves (41\%) e moderadas (52\%); fibrose presente em $51 \%$, no entanto, somente em sete pacientes $(2 \%)$ houve sinais de cirrose provável ou definitiva. Em uma delas havia acentuado alcoolismo.

A hepatite crônica por vírus C é doença de evolução variável. De maneira geral, sua evolução é lenta, insidiosa e progressiva.

Os pacientes que não apresentam evidências bioquímicas de lesão hepática, podem se constituir em subgrupo de casos "mais benignos", no curso natural da doença. Muitos co-fatores têm papel importante no desenvolvimento da cirrose nesses pacientes, como por exemplo, a idade no momento da infecção (os contaminados de idade mais avançada, têm evolução mais rápida da doença, enquanto que os mais jovens a têm mais lenta); o alcoolismo (é de consenso geral que o abuso de álcool favorece o aparecimento da cirrose) e a co-infecção com o vírus da SIDA e da hepatite B.

A incidência anual de carcinoma hepatocelular (CHC) é de $1 \%$ a $4 \%$ nos pacientes cirróticos, o que justifica plenamente o controle ecográfico do fígado e a dosagem sérica de alfa-fetoproteína nesses pacientes, a cada 1-2 anos. Por outro lado, nos pacientes com hepatite crônica por vírus $\mathrm{C}$ sem cirrose, o $\mathrm{CHC}$ é muito raro.

TREMOLADA et al. ${ }^{(29)}$, em 135 pacientes, encontraram $77 \%$ de hepatopatia crônica, sendo $32 \%$ destes com cirrose, após 7,5 anos de evolução.

Nos casos de cura, a atividade das transaminases cessa e os vírus não são detectados (VHC RNA) no soro. Nos casos de cronificação, acontece o contrário, ou seja, as alterações bioquímicas existem, com flutuações, e os vírus são detectáveis, na grande maioria dos casos. Fazem exceção aqueles pacientes com viremia baixa que, por isso mesmo, fogem aos limites dos métodos de detecção viral ou devido às flutuações próprias desses níveis virêmicos.

Nos pacientes anti-VHC positivos, com enzimas circulantes normais, a falta de VHC RNA no soro tem sido interpretada como sinal de cura completa. No entanto, HAYDON et al. ${ }^{(13)}$ alteraram essa interpretação. Estes autores demonstraram a presença de VHC RNA no fígado desses pacientes que eram negativos no soro, independente das alterações bioquímicas positivas ou negativas do soro, ou seja, mesmo naqueles casos anteriormente considerados como curados. Assim, os níveis de vírus intra-hepáticos não são determinados pelos fatores hospedeiro (idade, modo e duração da infecção) ou virais (VHC genotipos) pois, mesmo os repetidamente RT-PCR negativos para VHC RNA no soro podem ter vírus da hepatite $\mathrm{C}$ albergados no fígado. No entretanto, existem limitações metodológicas que devem ser consideradas nessa interpretação, como por exemplo, as limitações do RIBA 3 e do RT-PCR.
Mais importante é o seguimento dos pacientes ao longo do tempo. Assim, SEEF et al. ${ }^{(26)}$, em 568 pacientes de hepatite pós-transfusional e dois grupos controles pareados que receberam transfusões sem desenvolver hepatite, após 18 anos de seguimento, encontraram $3,3 \%$ de mortalidade no grupo 1 e $1,5 \%$ no grupo controle, sendo que a maioria das mortes ocorreu nos pacientes com alcoolismo associado. Parece, portanto, que a maioria que desenvolve doença crônica o faz muito lentamente.

Existem ainda, no curso natural da doença, flutuações intensas e muito freqüentes que dependem dos vírus e dos hospedeiros, a saber: níveis da viremia, genotipos $1 \mathrm{~b}$, graus de diversidade genética dos vírus, vias de transmissão (os inoculados via transfusão apresentam lesões hepatocelulares mais ativas $\left.{ }^{(11,12)}\right)$, deficiências imunes, alcoolismo e co-infecção com VHB e delta ${ }^{(30)}$ ou HIV $^{(20)}$. Nestes últimos casos, a co-infecção com múltiplos vírus das hepatites está associada com mais graves lesões histológicas do fígado do que nos casos de VHC isoladas.

Importa saber se os resultados obtidos com os controles feitos se mantêm por longos períodos. Ou seja, como exemplos, a atividade da ALT persistentemente normal, a variabilidade do RT PCR, a detecção de VHC RNA pela técnica do PCR que pode ser negativa, devido à inadequada armazenagem das amostras, à contaminação do soro com substâncias que interferem na leitura, entre outras causas de erro.

Por outro lado, as lesões histológicas, detectáveis em 100\% dos casos, acompanham-se de vírus presentes no tecido hepático.

As informações sobre as causas que determinam o curso evolutivo da doença são pouco conhecidas, apesar dos progressos havidos no campo do diagnóstico da infecção pelo VHC. Uma questão intrigante diz respeito à relação genotipo versus replicação viral e graus de lesão histológica. Assim, por exemplo, o genotipo 1 (1b) cursa com lesões histológicas mais graves, independentemente da carga viral. Ainda mais, os VHC RNA negativos no soro, mesmo após anos de "cura", podem recair, pois neles persistem os vírus no fígado, em regime de replicação muito baixa, indectável pelos métodos atuais. Ao contrário, os negativos no soro e no fígado, têm demonstrado respostas boas e sustentadas, inclusive no sentido de se fazer prognóstico de cura real e verdadeira, infelizmente na grande minoria dos casos.

OLIVEIRA et al. ${ }^{(24)}$, investigaram os padrões de distribuição dos genótipos do VHC, estudando 250 pacientes anti-VHC positivos, através da detecção VHC RNA pelo RT-PCR e encontraram prevalência de $72 \%$ para o VHC $1,25,3 \%$ para o tipo 3, $2 \%$ para o 2 e $0,7 \%$ para o 4, semelhantes aos das várias regiões mundiais.

BARBARO et al. ${ }^{(4)}$, verificaram que os pacientes VHC genotipos $1 \mathrm{~b}$, freqüentemente apresentavam alterações ultraestruturais das mitocondrias com depleição do mtDNA, podendo comprometer o processo de fosforilização oxidativa. Sendo assim, a produção aumentada de radicais livres nos pacientes VHC genotipos $1 \mathrm{~b}$, poderia atuar de modo 
negativo na evolução da doença hepática, aumentando o efeito citopático do vírus $\mathrm{C}$ da hepatite. Nesses pacientes, haveria portanto, aumento de hiperoxidação, com conseqüente resistência à ação dos interferons e pior evolução da doença hepática. A ser confirmado este fato, novas estratégias terapêuticas poderão vir a ser desenvolvidas no combate a essa doença.

AGNELLO et al. ${ }^{(1)}$, acreditam que a infecção persistente nessa doença, poderia ser devida à baixa percentagem de replicação viral nos hepatócitos. Esses autores usaram nova técnica de hibridização in situ para detectar VHC RNA, seis vezes mais específica do que a do RT-PCR. Concluem que a extensão da infecção hepatocítica varia inversamente ao índice de atividade histológica (IAH), ou seja, quando esta for mínima, aquela será máxima. No entanto, nesses casos, a concentração de VHC nos hepatócitos será muito baixa. Esses achados levam à hipótese de que a infecção persistente no fígado pode ser causada, ao menos em parte, por essa mesma baixa replicação viral.

Dos fatos acima expostos, decorrem implicações, tais como as respostas CD8-CTL aos antígenos VHC, restritas aos complexos de histocompatibilidade principais (MHC I), com inibição ou mesmo insuficiente produção de complexo peptídio VHC-MHC, inibição direta das células CTLK e a falta de resposta às citoquininas, entre outras, dos vários mecanismos de escape existentes. Dentro desse contexto, o nível de morte celular não seria alcançado e a lesão hepatocelular conseqüente seria, portanto, mínima.

Outra implicação resultante consiste na indução de resposta imune celular, T Helper mediadas, a partir de peptide vacinas contra $\mathrm{O}$ VHC. Estas novas vacinas têm a capacidade de gerar linfócitos $\mathrm{T}$ citotóxico os CTLs contra o VHC, em camundongo imunizados com peptídios CTL e células HT epítomes do core VHC. Esses estudos recentes ${ }^{(15)}$, em animais de laboratório, vêm progredindo rapidamente, esperando-se em breve, novos recursos no tratamento dessa doença.

\section{Em conclusão:}

a) a detecção de VHC RNA no fígado demonstra a existência de infecção residual, nos pacientes até então considerados "curados" clinicamente. Existiriam os "portadores sadios"? Parece que não;

b) as semelhanças entre pacientes virêmicos anti-VHC e a ausência de correlações entre os níveis e os graus de lesão hepática, favorecem o conceito da existência de mecanismos imune mediados, nessa doença.

c) a terapia anti-viral deve ser sempre considerada nos casos de VHC RNA negativos no soro, pois a grande maioria deles, tem os vírus albergados no fígado e, ao mesmo tempo, tem lesão hepática histologicamente demonstrável;

d) as mesmas precauções devem ser tomadas quanto à transmissibilidade nos pacientes anti-VHC (RIBA) positivos, independentemente da presença ou não de vírus no soro.

\section{Outros vírus associados}

YANG et al. ${ }^{(31)}$ e LINNEN et al. ${ }^{(19)}$ propuseram como agente etiológico responsável por alguns casos de hepatite crônica, nos quais os vírus $\mathrm{A}-\mathrm{E}$ foram excluídos, o vírus $\mathrm{G}$ da hepatite. Este novo vírus RNA, intimamente relacionado ao vírus GB-C (GBV-C), completamente diferente do VHC, GBH-A e GBV-B, permanece ainda com controvertida capacidade real de produzir lesões do tipo das hepatites agudas ou crônicas. Sua associação com o VHC existe em cerca de $20 \%$ dos casos de transfusões repetidas de sangue ou de seus derivados. Em conclusão, esta associação viral pode representar mais uma explicação para a grande resistência aos tratamentos desses pacientes, quando se utilizam os interferons.

Um novo vírus foi descoberto no Japão ${ }^{(23)}$, DNA linear denominado vírus transmitido por transfusão (VTT), provavelmente um parvovírus, cuja patogenicidade vem sendo intensamente estudada, em conjunto com a do vírus $\mathrm{G}$ da hepatite (VGH). Sua detecção em pacientes adultos com hepatopatias crônicas ou com evidências sorológicas correspondentes, tem sido de $10 \%$ a $38 \%$. Esses mesmos autores acreditam que o novo vírus (VTT) pode ser o responsável pela indução de hepatite pós-tranfusional, observada em três de seus pacientes.

Existem evidências de que a sua transmissão se faz por meio de transfusões.

SIMMONDS et al. ${ }^{(27)}$, utilizando o PCR, encontraram em três de cinco pacientes com hepatite pós-transfusional criptogênica, o VTT no plasma, com picos de viremia coincidentes com leves aumentos de ALT. Estes autores também investigaram a possível patogenia do VTT na insuficiência hepática aguda fulminante, não chegando a conclusões definitivas, porém, enfatizando a necessidade absoluta de maiores pesquisas clínicas quanto ao papel etiológico desse agente viral nas doenças hepáticas e extra-hepáticas.

NAOUMOV et al. ${ }^{(22)}$, em 12 adultos, 72 dos quais hepatopatas crônicos, 24 com resolução espontânea de VHC e 30 controles normais, utilizando a PCR, detectaram o VTT em $25 \%$ dos 72 pacientes hepatopatas, percentagem esta não diferente da prevalência de $10 \%$ nos controles normais $(P=0,15)$. A taxa de VTT DNA foi semelhante nos vários tipos de doenças do fígado, na presente casuística. A maioria dos VTT positivos não apresentou evidências histológicas ou bioquímicas de lesão hepática ativa. Os grupos de genotipos foram os mesmos dos identificados no Japão, ou sejam, genotipo 1 e 2 , em três e quatro pacientes, respectivamente.

Concluem que a alta prevalência de VTT na população geral tanto na Inglaterra, como no Japão, e a falta de significante lesão histológica de fígado associada, que o VTT, da mesma maneira que o VHG, pode ser mais um exemplo de vírus humano com obscura participação etiopatogênica. 


\section{Manifestações extra-hepáticas associadas aos vírus C da Hepatite}

É bastante provável que a persistência extremamente prolongada do vírus $\mathrm{C}$ da hepatite no hospedeiro, seu particular tropismo pelos hepatócitos e células mononucleares sangüíneas expliquem a importância e a freqüência desses comprometimentos extra-hepáticos da hepatite crônica por vírus $\mathrm{C}$.

Assim sendo, a infecção pelo $\mathrm{VHC}$ pode acometer, em ordem decrescente, diversos órgãos como a pele, o sistema músculo-articular, os nervos periféricos e os rins, comportando-se como verdadeira doença sistêmica.

Em estudos prospectivos recentes, CACOUB et al..$^{(6,7)}$, entre 1614 pacientes, estudaram $74 \%$ deles com pelo menos uma manifestação extra-hepática, em ordem decrescente: artralgias, parestesias, mialgias, prurido e síndrome sica. Além disso, $53 \%$ deles apresentaram ao menos uma anomalia biológica extra-hepática, na mesma ordem decrescente: crioglobulinas, anticorpos antinucleares, tiroxinemia baixa, anticorpos anti-músculo liso. Dentro da natural complexidade do problema, cumpre ressaltar quatro aspectos principais, ou sejam: 1) o comprometimento extra-hepático certamente ligado ao VHC; crioglobulinas mistas, nefropatias glomerulares membranoproliferativas, porfiria cutânea tardia, produção de auto-anticorpos, síndrome sica; 2) comprometimento extra-hepático possivelmente ligado à infecção pelo VHC: linfoproliferações malignas, vascularites sistêmicas, trombocitopenia autoimune, prurido, manifestações articulares e musculares; 3) comprometimento extra-hepático com associação aparentemente fortuita do VHC: úlcera córnea de Mooren, fibrose pulmonar, poliradiculoneurite crônica, eritema nodoso, diabetes sacarino, leucoencefalite multifocal progressiva; 4) comprometimentos extra-hepáticos favorecidos ou desencadeados pelos tratamentos anti-VHC: distiroidites, psoríase, sarcoidose, líquen, neuropatias periféricas. Em nosso meio, STRAUSS ${ }^{(28)}$ publicou quatro casos de crioglobulinemia mista associados à hepatite $\mathrm{C}$.

\section{Comentários finais}

A identificação, em 1989, do vírus $C$ da hepatite como o principal agente causal das hepatites não-A não-B, foi seguida pelo reconhecimento da alta prevalência da infecção $\mathrm{VHC}$ após transfusões de sangue ou de seus produtos de origem contaminados, associados ao abuso de drogas endovenosas.

A crescente disponibilidade de técnicas cada vez mais sensíveis e confiáveis para selecionar os doadores sadios verdadeiros, reduziu substancialmente a incidência das hepatites pós-transfusionais.

Os estudos sobre a história natural da doença, repousam na existência de casos esporádicos de infecção iatrogênica, em particular quando se necessitam períodos de vários anos de observação. Esses estudos levaram a várias conclusões, dentre as quais ressaltou a de que o VHC determina, na grande maioria das vezes, doença hepática de evolução lenta e progressiva, atestada pela elevada concentração de ALT no soro, em mais da metade dos pacientes infectados e da presença de sinais histológicos de inflamação (em cerca de $90 \%$ dos casos) e de fibrose (em cerca der $50 \%$ deles), no material obtido através de biopsia de fígado.

Cerca de $60 \%$ dos pacientes, após surto agudo da doença, desenvolvem hepatite crônica, cerca de $25 \%$ deles assintomática, com ALT normais e alterações histológicas mínimas, assim permanecendo por vários anos, até a sua detecção mediante pesquisa diagnóstica laboratorial apropriada.

Existe cura espontânea, após surto agudo da doença, em cerca de $15 \%$ dos pacientes portadores de VHC.

O prognóstico da doença a longo prazo é mal conhecido, porém admite-se no consenso geral, que a grande maioria dos pacientes não morre da sua doença hepática.

Cerca de $20 \%$ dos pacientes de hepatite crônica por vírus C desenvolvem cirrose hepática 10 a 20 anos depois, passível de transplante hepático, não afetando a duração média da vida da maioria desses pacientes.

Muitos co-fatores têm importante papel no desenvolvimento da cirrose, como por exemplos, a idade no momento da contaminação (os mais idosos têm evolução mais rápida do que os mais jovens), o alcoolismo (acelera o seu aparecimento), a co-infecção com o vírus SIDA e o das hepatites B e D, agravam a evolução da doença.

A incidência de $\mathrm{CHC}$ nos pacientes cirróticos é de $1 \%$ a $4 \%$, o que justifica plenamente o controle sistemático com ultra-sonografia do fígado e dosagem sérica de alfa-fetoproteína.

Nos não-cirróticos, portadores de hepatite crônica, o $\mathrm{CHC}$ é raro.

Os testes diagnósticos mais usuais são os ELISA 2, muito confiáveis nos pacientes imunocompetentes.

Nos doadores de sangue e na população geral, pode haver até $25 \%$ de falso-positivos, que devem ou não ser confirmados com os testes RIBA.

Nos casos suspeitos de hepatite crônica por vírus $\mathrm{C}$ ou nos de alto risco, o teste ELISA 2 positivo deve ser confirmado com um teste qualitativo $\mathrm{ARN}$ da hepatite crônica por vírus $\mathrm{C}$.

A genotipagem e os testes quantitativos ARN VHC devem ser feitos apenas quando da necessidade de tratamento medicamentoso específico.

As pessoas que devem ser testadas para o vírus $\mathrm{C}$ da hepatite são todos aqueles que receberam produtos de origem sangüínea, antes do advento dos ELISA 2 (1991), os hemofílicos, os hemodialisados, as crianças de mães portadoras de hepatite $\mathrm{C}$, os toxicômanos intravenosos atuais ou passados (mesmo os de curta duração) e os doadores de tecidos ou órgãos.

As duas principais fontes de contaminação na hepatite crônica por vírus $C$ são a toxicomania endovenosa e a administração de pro- 
dutos do sangue. A última praticamente desapareceu depois do aparecimento dos testes ELISA 2.

A transmissão sexual é raramente observada; fazem exceção as pessoas com relações sexuais com múltiplos parceiros, nestes está indicado o uso de preservativos.

A gravidez não está contra-indicada nas mulheres infectadas com o vírus $\mathrm{C}$ da hepatite, nem os testes diagnósticos devem ser feitos de rotina nas mulheres grávidas, pois a transmissão vertical é baixa, inferior a $6 \%$. O risco aumenta nas pacientes com forte viremia e ou coinfecção com o vírus da SIDA. O parto natural ou cesárea não tem influência sobre a transmissão do VHC da mãe para o filho. O aleitamento materno não está associado à transmissão mãe-criança do VHC.

Quanto à fecundação in vitro, não existem dados suficientes para conclusões.

As transmissões hospitalares são eficazmente combatidas pelos métodos de prevenção habituais.

A sintomatologia clínica apresentada pelos 150 milhões de pacientes infectados existentes no mundo todo é muito variável, preferentemente fadiga, em cerca de $2 / 3$ deles, artralgias ou mialgias, em cerca de $30 \%$ e, numa minoria (10\%), ansiedade e depressão, estas duas últimas provavelmente devidas ao trauma emocional provocado pela desconhecida potencialidade nóxia da doença que albergam.

Em relação aos critérios de cura nessa afecção, houve profundas alterações, a partir de 1998. Até então, admitia-se nos pacientes antiVHC positivos, com enzimas circulantes normais e falta de VHC RNA detectável no soro, pela técnica do PCR, a cura completa e o tratamento era suspenso. No entanto, verificou-se que nesses pacientes, poderiam haver recaídas, devidas aos baixos níveis de replicação viral existente no fígado, replicação essa indetectável pelos métodos atuais disponíveis.

Ao contrário, os pacientes negativos no soro e no fígado, ou sejam, os PCR VHC RNA persistentemente negativos, com respostas terapêuticas positivas e sustentadas, poderiam ser considerados verdadeiramente curados, que infelizmente representam a grande minoria deles.

A patogênese do VHC não está ainda bem caracterizada. Resta saber se o vírus tem efeito citopático direto ou não, além de uma explicação aceitável para a sua persistência e replicação tecidual hepática.

Os achados histológicos hepáticos nos infectados variam bastante e ao final, parecem representar uma complexa interação vírus-hospedeiro.

Novos enfoques sobre a patogênese surgiram com o encontro de alterações ultraestruturais mitocondriais, nos fragmentos de fígado obtidos por biopsia nos pacientes cronicamente infectados pelos VHC. Essas alterações envolvem processos de peroxidação lipídica e, conseqüentemente, o estresse oxidativo.

As mitocondrias apresentam-se irregulares, espessadas e com fragmentação de crista. Isto poderia explicar o porque da esteatose tão freqüente nesses pacientes, em particular, nos infectados pelos genotipos $1 b$.

Verificou-se, também, que essas alterações mitocondriais associam-se freqüentemente à depleição tecidual de glutathione - um antioxidante celular. A perda deste último pode ser devida à excessiva produção de oxidantes. $\mathrm{O}$ estresse oxidativo também pode ser responsabilizado pela peroxidação lipídica.

O que ocorreria primeiro? Seria o VHC diretamente responsável pela disfunção mitocondrial que, subseqüentemente, levaria ao estresse oxidativo, ou então, haveria produção excessiva de radicais livres decorrentes do processo inflamatório produzido pelo $\mathrm{VHC}$, com alterações mitocondriais conseqüentes?

Sabe-se, por outro lado, que a disfunção mitocondrial é, por si só, importante fator citotóxico, provocando apoptose, com liberação de citocromo C e AIFC (apoptosis-inducing factors) que, por sua vez, promovem ativação de proteases, caspase, família de proteases implicadas na apoptose. Essas caspases produzem cisão proteolítica de células mortas, culminado com a citotoxicidade.

Assim sendo, os VHC poderiam induzir a disfunção mitocondrial por atuação das suas proteínas virais sobre as mitocondrias, ou então, induzindo o estresse oxidativo intracelular, ou ainda, por ativação imunemediata da apoptose através do sistema Fas ou/e finalmente, por associação de estresse oxidativo à inflamação celular produzida pelo próprio vírus, tendo como alvo final, as mitocondrias.

Do ponto de vista prático estes conhecimentos poderiam ser aplicados e justificar o uso de alfa-tocoferol e de inibidores de caspase, no combate à doença em causa.

Como conseqüência, e de maneira imbricada, a baixa replicação viral intra-hepática e as alterações ultraestruturais mitocondriais, ocasionariam alterações de bases imunes, com inibição ou mesmo insuficiente produção de complexo peptídio VHC-MHC, inibição de células CTLK e falta de resposta às citoquinas.

Dentro desse contexto, o nível de morte celular não seria alcançado (apoptose) e a lesão hepatocelular seria mínima.

Outros vírus como o vírus $\mathrm{G}$ da hepatite (VHG) e o vírus transmitido pela transfusão (VTT), no consenso geral, parecem não representar papel etiopatogênico importante nas hepatites não-A, não-B, constituindo-se como exemplos de participação ainda um tanto obscura nesse grupo de afecções que ora acabamos de apresentar.

Quanto às manifestações extra-hepáticas, diga-se que o tratamento da hepatite $\mathrm{C}$ tanto pode promover a resolução clínica e bioquímica da doença, no conjunto, como também favorecer ou precipitar sua eclosão.

No entanto, é de boa conduta, em casos de crioglobulinemia, por exemplo, pesquisar o vírus $\mathrm{C}$ e nos casos positivos, tratar adequadamente, mesmo na ausência de sinais de hepatopatia ativa, respeitando as contra-indicações formais desse tratamento. 
Conte VP. Hepatitis C virus. Part 1. General considerations. Arq Gastroenterol 2000;37(3):187-194.

ABSTRACT - Hepatitis C virus was identified in 1989 as the main causative agent of non- $A$, non- $B$ and was followed by the recognition of a high prevalence of hepatitis $C$ virus infection after transfusion of infected blood or blood products and in association with intravenous drug abuse. The availability of sensitive and reliable techniques to screen blood for hepatitis $C$ virus has reduced the incidence of posttransfusion hepatitis. True healthy carriers of hepatitis $C$ virus did not exist. Aproximately $95 \%$ of hepatitis $C$ virus infected individuals can be identified by third generation anti-hepatitis $C$ virus testing. Retrospective studies of iatrogenic hepatitis $C$ virus infection are the main source of the natural history of the disease. The distribution of different hepatitis $C$ virus genotypes varies according to the grographic region. In South America, Europe, The United States and Japan hepatitis C virus genotypes 1, 2 and 3 account for the majority of the infections, being (sub)type $1 b$ the most prevalent. Epidemiological parameters (age, risk factors and duration of infection) may be associated with hepatitis $C$ virus genotypes (intravenous drug abuse with types 1-a and 3-a and 1-b with post-transfusion hepatitic C). Subtype 1-b, lead to a more severe course of viral infection, with ultrastructural alterations of the mitochondria, and greater impairment of the process of oxidative phosphorylation. No increased production of free radicals may influence the evolution of the liver disease by an enhancement of the cytopathic effect of hepatitis $C$ virus. The clinical significance of intrahepatic hepatitis $C$ virus level in patients with chronic hepatitis $C$ virus infection is not determined by host factors (age of patient, mode or duration of infection) or by virus factors (hepatitis $C$ virus genotypes) and, repeatedly negative RT-PCR for hepatitis C virus RNA in serum does not indicate absence of hepatitis $C$ virus from the liver. The association between autoimmunity and hepatitis $C$ virus is questioned. Markers of its does occur with high frequency in these patients. Modulation of immune responses to hepatitis $C$ virus envelope 22 protein following injection of plasmid DNA, has been used for induction of specific response to hepatitis $C$ virus. The spectrum of such responses could likely be broadened by combining plasmids, delivery routes, and other forms of encoded immunogens (peptide vaccines). These may be important to the development of a vaccine against the high mutable hepatitis $C$ virus. The pathogenic role of novel DNA virus (TTV) is under spotlight. As with hepatitis G, however, the association of TTV with disease is far from clear.

HEADINGS - Hepatitis C.

\section{REFERÊNCIAS BIBLIOGRÁFICAS}

1. Agnello V, Abel G, Knight GB, Muchmore E. Detection of widespread hepatocyte infection in chronic hepatitis C. Hepatology 1998;28:573-84.

2. Almeida PRL, Mattos AA, Peixoto MF, Both CT. Estudo clínico, laboratorial e histológico em doadores de sangue anti-HVC positivos. GED Gastroenterol Endosc Dig 1999;18:85-90.

3. Alter MJ, Margolis HS, Krawczynski K, Judson FN, Mares A, Alexander WJ, Hu PY, Miller JK, Gerber MA, Sampliner RE. The natural history of communityacquired hepatitis $\mathrm{C}$ in the United States. The sentinel counties chronic non-A, non-B hepatits study team. N Engl J Med 1992;327:1899-905.

4. Barbaro G, Di Lorenzo G, Asti A, Ribersani M, Belloni G, Grisorio B, Filice G, Barbarini G. Hepatocellular mitochondrial alterations in patients with chronic hepatitis C: ultrastructural and biochemical findings. Am J Gastroenterol 1999;94:2198-205.

5. Berenguer W. Is the hepatocyte a Troja horse for hepatitis C virus? Gut 1998;42:456-8.

6. Cacoub P, Poynard T, Ghilani P, Charlotte F, Olivi M, Piette JC, Opolon P. Extrahepatic manifestations of chronic hepatitis C. MULTIVIRC Group. Multidepartment Virus C. Arthritis Rheum 1999;42:2204-12.

7. Cacoub P, Piette JC. Les manifestations extra-hépatiques associées au virus de l'hépatite C (avant-propos). Ann Med Interne (Paris) 2000;151:19.

8. Choo QL, Kuo G, Weiner AJ, Overby LR, Bradley DW, Houghton M. Isolation of a CDNA clone derived from a blood born non-A, non-B viral hepatitis genome. Science 1989;244:359-62.

9. Delaporte E, Thiers V, Dazza MC, Romeo R, Mlika-Cabanne N, Aptel I, Schrijvers D, Brechot C, Larouze B. High level of hepatitis C endemicity in Gabon, equatorial Africa. Trans R Soc Trop Med Hyg 1993;87:636-7.

10. Esteban JI, Esteban R, Viladomiu L, Lopez-Talavera JC, Gonzalez A, Hernandez JM, Roget M, Vargas V, Genesca J, Buti M. Hepatitis C virus antibodies among risk group in Spain. Lancet 1989;334:294-7.
11. Gordon SC, Bayati N, Silverman AL. Clinical outcome of hepatitis C as a function of mode of transmission. Hepatology 1998;28:562-7.

12. Gordon SC, Elloway RS, Long JC, Dmuchowski CF. The pathology of hepatitis $\mathrm{C}$ as a function of mode of transmission: blood transfusion vs intravenous drug use. Hepatology 1993;18:1338-43.

13. Haydon GH, Jarvis LM, Blair CS, Simmonds P, Harrison DJ, Simpson KJ, Hayes PC. Clinical significance of intrahepatic hepatitis $C$ virus levels in patients with chronic HVC infection. Gut 1998;42:570-5.

14. Hiranuma K, Tamaki S, Nishimura Y, Kusuki S, Isogawa M, Kim G, Kaito M, Kuribayashi K, Adachi Y, Yasutomi Y. Hepatitis V viral particle detected by immunoelectron microscopic study. J Gen Virol 1994;75:1755-60.

15. Hiranuma K, Tamaki S, Nishimura Y, Kusuki S, Isogawa M, Kim G, Kaito M, Kuribayashi K, Adachi Y, Yasutomi Y. Helper T cell determinant peptide contributes to induction of cellular immune responses by peptide vaccines against hepatitis C virus. J Gen Virol 1999;80:187-93.

16. Karmochkine M, Carrat F, Valleron AJ, Raguin G. Modes de transmission du virus de l'hepatite C. Presse Med 1998;27:871-6.

17. Kenny-Walsh E, The Irish Hepatology Research Group. Clinical outcomes after hepatitis $\mathrm{C}$ infection from contamined anti-D immune globulin. N Engl J Med, 1999;340:1228-33.

18. L'European Association for the Study of the Liver (EASL), Paris. Conférence Internationale de Consesus sur L'hépatite C. Conclusions. Gastroenterol Clin Biol 1999;23:730-5.

19. Linnen J, Wages J Jr, Zhang-Keck ZY, Fry KE, Krawczynski KZ, Alter H, Koonin E, Gallagher M, Alter M, Hadziyannis S, Karayannis P, Fung K, Nakatsuji Y, Shih JW, Young L, Piatak M Jr, Hoover C. Molecular cloning and disease association of hepatitis G virus: a transfusion-transmissible agent. Science $1996 ; 271 ; 505-8$.

20. Martin P, Di Bisceglie AM, Kassianides C, Lisker-Melman A, Hoofnagle JH. Rapidly progressive non-A, non-B hepatitis in patients with human immunodeficiency virus infection. Gastroenterology 1989;97:1559-61. 
21. Mutimer DJ, Harrison RF, O’Donnell KB, Shaw J, Martin BA, Atrah H, Ala FA, Skidmore S, Heuberger JM. Hepatitis $\mathrm{C}$ virus infection in the asymptomatic British blood donor. Viral Hepat 1995;2:47-53.

22. Naoumov NV, Petrova EP, Thomas MG, Williams R. Presence of a newly described human DNA virus (TTV) in patients with liver disease. Lancet 1998;352:195-7.

23. Nishizawa T, Okamoto H, Konishi K, Yooshizawa H, Miyakawa Y, Mayumi M. Novel DNA virus (TTV) associated with elevated transaminase levels in posttransfusion hepatitis of unknown etiology. Biochem Biophys Res Comm 1997;241:92-7

24. Oliveira MLA, Bastos FI, Sabino RR, Paetzold U, Schreier E, Pauli G, Yoshida CFT. Distribution of HVC genotypes among different exposure categories in Brazil. Braz J Med Biol Res 1999;32:279-82.

25. Saeed AA, Al-Admawi AM, Al-Rasheed A, Fairclough D, Bacchus R, Ring C, Garson J. Hepatitis C virus infection in Egyptian volunteer blood donors in Riyadh [letter]. Lancet 1991;338:459-60.

26. Seef LB, Buskell-Bales Z, Wright EC, Durako SJ, Alter HJ, Iber FL, Hollinger FB, Gitnick G, Knodell RG, Perrillo RP. Long-term mortality after transfusionassociated non-A, non-B hepatitis. N Engl J Med 1992;327:1906-11.

27. Simmonds P, Davidson F, Lycett C, Prescott LE, MacDonald DM, Ellender J, Yap DL, Ludlam CA, Haydon GH, Gillon J, Jarvis LM. Detection of a novel DNA virus (TTV) in blood donors and blood products. Lancet 1998;352:191-5.
28. Strauss E. Crioglobulinemia mista e hepatite C: relato de quatro casos. GED Gastroenterol Endosc Dig 2000;19:166-70.

29. Tremolada F, Casarin C, Alberti A, Drago C, Tagger A, Ribeiro ML, Realdi G Long-term follow-up of non-A, non-B (type C) post-transfusion hepatitis. J Hepatol 1992;16:273.

30. Weltman MD, Brotodihardjo A, Crewe EB, Farrell GC, Bilous M, Grierson JM, Liddle C. Coinfection with hepatitis $\mathrm{B}$ and $\mathrm{C}$ or $\mathrm{B}, \mathrm{C}$ and delta viruses results in severe chronic liver disease and responds poorly to interferon-alpha treatment. J Viral Hepat 1995;2:39-45.

31. Yang G, Caroli-Bosc FX, Laffont C, Bianchi D, Dantin S, Lefebre JC, Doglio A Hepatitis $\mathrm{G}$ and $\mathrm{C}$ viruses respond to interferon alfa with different virologic kinetics. Dig Dis Sci 1998;43:1307-10.
Recebido para publicação em 2/3/1999. Aprovado para publicação em 22/7/1999. Atualizado em 11/9/2000. 